\title{
Regulation and Physiological Functions of G12/13-Mediated Signaling Pathways
}

\author{
Nobuchika Suzuki ${ }^{a}$ Nicole Hajicek ${ }^{b}$ Tohru Kozasa ${ }^{a, b}$ \\ a Laboratory of Systems Biology and Medicine, Research Center for Advanced Science and Technology, \\ The University of Tokyo, Tokyo, Japan; ${ }^{b}$ Department of Pharmacology, University of Illinois at Chicago, \\ Chicago, III., USA
}

\section{Key Words}

Regulation of G12/13-mediated signaling pathways •

Ga12/13-RH-RhoGEF-Rho pathway · Regulation of

G12/13 - Regulation of effectors by G12 - Crosstalk between

G12/13-mediated and other signaling pathways •

Cell proliferation and transformation - Cell morphology and motility - The cardiovascular system $\cdot$ The immune system $\cdot$ The neuronal system

\begin{abstract}
Accumulating data indicate that $\mathrm{G} 12$ subfamily $(\mathrm{G} \alpha 12 / 13)$ mediated signaling pathways play pivotal roles in a variety of physiological processes, while aberrant regulation of this pathway has been identified in various human diseases. It has been demonstrated that G $\alpha 12 / 13$-mediated signals form networks with other signaling proteins at various levels, from cell surface receptors to transcription factors, to regulate cellular responses. G $\alpha 12 / 13$ have slow rates of nucleotide exchange and GTP hydrolysis, and specifically target RhoGEFs containing an amino-terminal RGS homology domain (RH-RhoGEFs), which uniquely function both as a GAP and an effector for $G \alpha 12 / 13$. In this review, we will focus on the mechanisms regulating the $G \alpha 12 / 13$ signaling system, particularly the Ga12/13-RH-RhoGEF-Rho pathway, which can regulate a wide variety of cellular functions from migration to transformation.

Copyright $\odot 2009$ S. Karger AG, Base
\end{abstract}

\section{Introduction}

The $\alpha$ subunits of heterotrimeric G proteins are classified into four subfamilies based on the homology of their amino acid sequences: Gs, Gi, Gq, and G12 [1]. The

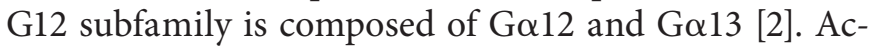
cumulating evidence indicates that G12/13-mediated signaling pathways are involved in a variety of physiological processes, including embryonic development, cell growth, cell polarity and migration, angiogenesis, platelet activation, the immune response, apoptosis, and neuronal responses [3-15]. In the nervous system, this pathway plays an important role in neuronal migration, axonal guidance, formation of cerebellar and cerebral cortices, and neurotransmitter release [11, 16-20]. In addition, abnormal regulation of this pathway has been found in disease conditions such as leukemia, cell transformation, tumor cell invasion and metastasis, hypertension, and ataxia [14, 18, 21-27]. However, significant differences between G $\alpha 12$ and $G \alpha 13$ signaling have been demonstrated from knockout mouse studies [28, 29]. Crosstalk between $\mathrm{G} \alpha 12 / 13$ signaling and other $\mathrm{G}$ protein signals, especially from $\mathrm{G} \alpha \mathrm{q}$, have also been reported [3, 11, 28, 30-36]. These results suggest that Go12/13-mediated signaling pathways will play a critical role in many important biological responses. In this review, we will focus on the mechanisms by which the $\mathrm{G} \alpha 12 / 13$ signaling system regulates a wide variety of cellular functions.

\section{KARGER}

Fax +4161306 1234 E-Mail karger@karger.ch www.karger.com

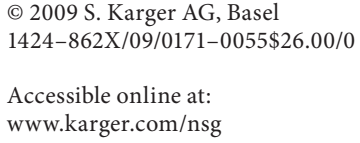

Laboratory of Systems Biology and Medicine

Research Center for Advanced Science and Technology

The University of Tokyo, Tokyo (Japan)

Tel. +81 35452 5356, Fax +81 5452 5356, E-Mail suzuki-n@lsbm.org 


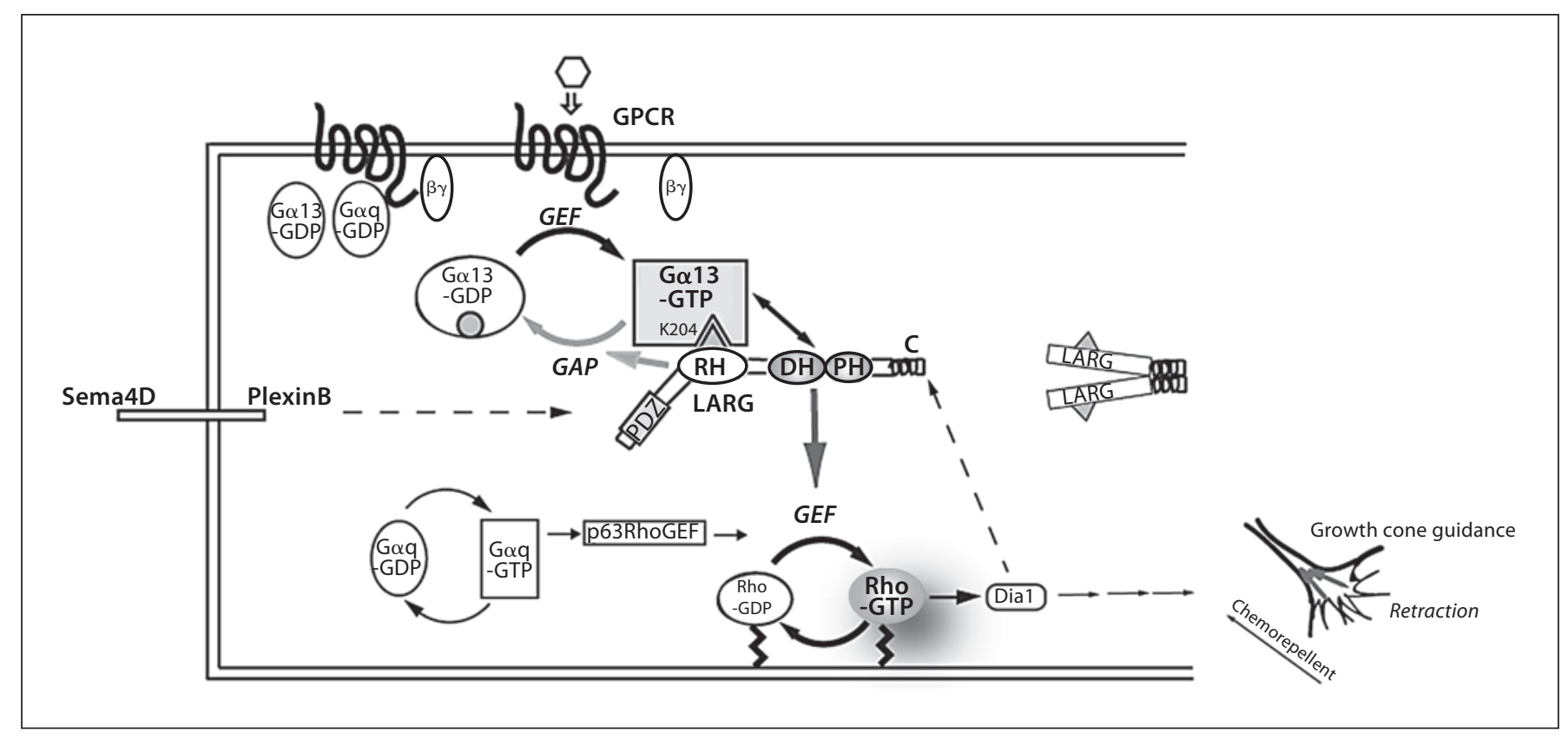

Fig. 1. The G12/13-mediated signaling pathway interacts with diverse proteins at various levels. Upon ligand binding, GPCRs catalyze the exchange of GDP for GTP on G $\alpha 13$ subunits resulting in activation of the $\mathrm{G} \alpha$ subunit and release of G $\beta \gamma$. Both G $\alpha$-GTP and free $G \beta \gamma$ interact with diverse downstream effectors. LARG is an effector for G $\alpha 13$, which is a GEF for the monomeric GTPase RhoA. Upon binding of G 13 -GTP to LARG, the DH/PH domains activate RhoA by facilitating the exchange of GDP for GTP. LARG, in turn, stimulates the intrinsic GTPase activity of G $\alpha 13$ through its $\mathrm{N}$-terminal $\mathrm{RH}$ domain. G $\alpha$-GDP dissociates from effectors and reassociates with G $\beta \gamma$ to terminate the signal. Thus, regulation of the $G$ protein cycle of activation and deactivation profoundly affects the cellular response. The amplitude and duration of the signal response are determined by the amount of GTPbound $G \alpha$ subunit. A dotted line indicates evidence for direct activation of LARG without activated G $\alpha 13$. Domains: $R H=R G S$ (regulator of $\mathrm{G}$ protein signaling) homology; $\mathrm{DH}=\mathrm{Dbl}$ homology; $\mathrm{PH}=$ pleckstrin homology; PDZ = PSD-95/SA90-Discs-large$\mathrm{ZO}-1$. See the text for details.

drolyzes bound GTP to GDP by its intrinsic GTPase activity and this deactivation process is further accelerated by GTPase-activating proteins (GAPs) such as regulator of $\mathrm{G}$ protein signaling (RGS) proteins $[39,40]$. G $\alpha$-GDP dissociates from effectors and reassociates with $G \beta \gamma$ to terminate the signal. Thus, regulation of $G$ protein cycles of activation and deactivation profoundly affect the cellular responses and the amplitude and duration of the signal response are determined by the amount of GTPbound $\mathrm{G} \alpha$ subunit.

\section{Regulation of $G 12 / 13$}

Activation of G12/13 by GPCRs

More than 30 GPCRs are reported to couple to either G12, G13 or both, based on direct or indirect methods of evaluating $\mathrm{G}$ protein activation; see details in Riobo and Manning's review [41]. It is believed that the binding of a ligand changes the conformation of critical regions of the seven-transmembrane helix pocket of the GPCR, which 
in turn causes conformational changes in the intracellular loops and $\mathrm{COOH}$ terminus. However, the precise activation mechanism of $G$ proteins by agonist-activated GPCRs remains unknown.

In general, interaction between the C-termini of $\mathrm{G} \alpha$ and GPCRs is considered to be responsible for $\mathrm{G} \alpha$ activation. Although the exact interface between $\mathrm{G} \alpha 12 / 13$ and GPCRs remains unclear, antibodies against the C-termini of $G \alpha 12$ or $G \alpha 13$ subunits or peptides corresponding to $10-50$ residues of the $\mathrm{C}$-termini specifically attenuate the agonist-activated angiotensin (AT1), thrombin, and sphingosine-1-phosphate (S1P2 and S1P3) receptor signals in cells $[25,42,43]$. In addition, the $\mathrm{N}$-terminal short sequences of $\alpha$ subunits of the G12 family, where G $\alpha 12$ and $\mathrm{G} \alpha 13$ have low amino acid sequence homology, are reported to determine the selectivity of coupling to receptors [25, 42-44]. The use of chimeric G $\alpha 12$ and $G \alpha 13$ proteins, in which the $\mathrm{N}$-terminal short sequences are replaced with each other, demonstrated that thrombin and

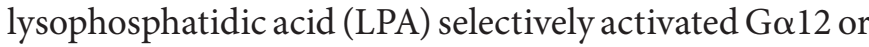
Ga13 expressed in HEK 293 cells. From studies of other $\mathrm{G} \alpha$ subfamilies, membrane-proximal regions of the second and third intracellular loops and the cytoplasmic tail of the receptor are generally believed to have an important role in $\mathrm{G} \alpha$ activation $[45,46]$.

Many GPCRs are reported to simultaneously couple to and activate more than one $G$ protein subfamily member [45]. Studies suggest that most receptors coupling to the G12 subfamily could couple to both G12 and G13, except for the 5-hydroxytryptamine 4 receptor, which only couples to G13 [41, 47]. Furthermore, most receptors coupling to $\mathrm{G} \alpha 12$ and/or $\mathrm{G} \alpha 13$ couple to other G proteins, especially to $\mathrm{G} \alpha \mathrm{q}[41,45,48]$. These facts make evaluating the specificity of the signaling through G12 and G13 complicated. To analyze signaling through a specific receptor-G protein pair, Zhang et al. [48] evaluated $\mathrm{G} \alpha$ activation directly and in 1:1 stoichiometry using thromboxane $A_{2}$ receptor $(\mathrm{TP} \alpha)-\mathrm{G} \alpha 12$ or -G $\alpha 13$ fusion proteins in Spodoptera frugiperda (Sf9) cells. Interestingly, the results show that $\mathrm{TP} \alpha-\mathrm{G} \alpha 12$ responded to agonists with slow GTP $\gamma S$ binding, whereas the TP $\alpha-G \alpha 13$ response was fast. These results contrast with the case of the purified $\mathrm{G} \alpha$ proteins in vitro: $\mathrm{G} \alpha 12$ and $\mathrm{G} \alpha 13$ do not show any differences in GTP $\gamma S$ binding kinetics. Ligand binding may induce a specific conformational change in $\mathrm{TP} \alpha$ to influence the coupling efficiency to different $\mathrm{G} \alpha$ subunits. In turn, it is also possible that binding with specific $\mathrm{G} \alpha-\mathrm{GDP}$ subunits may change the conformation of the receptor to define the affinity of the ligand for the receptor. Alternatively, the selectivity might be enhanced in collaboration with associated proteins in the cell. Future structural analysis of a complex of a GPCR with heterotrimeric $\mathrm{G} \alpha 12 / 13$ proteins will provide information critical for answering these questions.

Deactivation of $\mathrm{G} \alpha 12 / 13$ by RGS Proteins

Like all other heterotrimeric $\mathrm{G}$ protein $\alpha$ subunits, G $\alpha 12 / 13$ cycle between GDP- (inactive) and GTP-bound (active) states and possess an intrinsic ability to hydrolyze GTP to GDP. In vitro analysis has demonstrated that both recombinant $G \alpha 12$ and $G \alpha 13$ proteins have relatively slow rates of nucleotide exchange and GTP hydrolysis (G $\alpha 12: \mathrm{k}_{\mathrm{on}}, \mathrm{GTP} \gamma \mathrm{S}=0.01 \mathrm{~min}^{-1}, \mathrm{k}_{\mathrm{cat}}=0.1-0.2 \mathrm{~min}^{-1}$, G $\left.\alpha 13: \mathrm{k}_{\text {off }}, \mathrm{GDP}=0.01 \mathrm{~min}^{-1}, \mathrm{k}_{\mathrm{cat}}=>0.2 \mathrm{~min}^{-1}\right)[49,50]$. This deactivation process is accelerated by the GAP activity of RGS proteins. p115RhoGEF and leukemia-associated RhoGEF (LARG) have been shown to act as specific GAPs for $\mathrm{G} \alpha 12$ and $\mathrm{G} \alpha 13$ in vitro [51-53]. p115RhoGEF, LARG, and PDZ-RhoGEF/GTRAP48 are the known members of the mammalian RhoGEF family, which contain an amino-terminal RGS homology (RH, also called rgRGS) domain (RH-RhoGEFs) that recognizes activated $\mathrm{G} \alpha 12 / 13$ [54-57] (fig. 2). In addition, $\mathrm{RH}$ RhoGEFs contain central DH/PH (Dbl homology/pleckstrin homology) domains characteristic of GEFs for Rho family GTPases. In vitro, p115RhoGEF and LARG act as specific GAPs for $G \alpha 12$ and $G \alpha 13$, while the RGS domain of PDZ-RhoGEF lacks detectable GAP activity for these

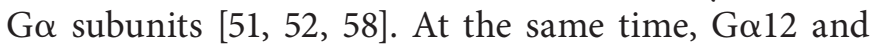
G $\alpha 13$ subunits regulate the activity of Rho through RHRhoGEFs [51-53, 55, 58]. RH-RhoGEFs directly link the activation of GPCRs by extracellular ligands to the regulation of Rho activity in cells. RH-RhoGEFs combine GAP and effector activity into a single molecule to regulate signaling from $\mathrm{G} \alpha 12 / 13$.

Although the sequence identity between the RGS domains from RH-RhoGEFs and other RGS family members is low (between 10 and 15\%) [51], the high resolution crystal structures of the RGS domains from both PDZRhoGEF and p115RhoGEF have demonstrated that these domains share a similar tertiary fold composed of an allalpha helical bundle $[59,60]$. One structural divergence between these RGS domains and RGS4 is the extended C-terminus found in the RH-RhoGEFs, which forms $\alpha$ helices tightly associated with the core RGS domain through a large hydrophobic surface.

Site-directed mutagenesis of both Go13 and p115RhoGEF has provided important insights into the mechanism of the acceleration of GTPase activity by the RH domain of p115RhoGEF. In G $\alpha 13$, lysine 204, located 
in its switch I region, has been shown to be important for interaction with the RH domains of both p115RhoGEF and LARG $[61,62]$. Residues 1-252 of p115RhoGEF stimulate the GTPase activity of G $\alpha 13$ similarly to the fulllength protein $[51,53]$. It has been demonstrated that residues at the $\mathrm{N}$-terminus of the $\mathrm{RH}$ domain are required for RH-RhoGEFs to exert their GAP activity [53, 63]. In particular, residues $27-31$ within a negatively charged cluster of residues are crucial for p115RhoGEF's GTPase activity. Mutations in this acidic patch reduce both binding to $\mathrm{G} \alpha 13$ and stimulated GTP hydrolysis $[63,64]$. Furthermore, a structural study of a complex between p115RhoGEF's RH domain and a Go13/i1 chimera has demonstrated that the interface is different from that of the RGS domain of RGS4 and Gail [54]. The N-terminal small element within the RH domain, which is required for GAP activity towards G $\alpha 13$, contacts the switch re-

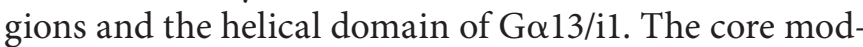
ule of the $\mathrm{RH}$ domain binds to the switch II region and the $\alpha 3$ helix of G $\alpha 13 / \mathrm{il}$ chimera, which is used for effector binding in other $\mathrm{G} \alpha$ subunits. In spite of these structural studies, the molecular mechanism of GAP and GEF activation of RH-RhoGEFs upon G $\alpha 12 / 13$ binding has not yet been elucidated.

\section{Post-Translational Modification of G $\alpha 12 / 13$}

Lipid modifications affect the subcellular localization of $G \alpha$ subunits and the interactions of these subunits with other proteins. G $\alpha$ subunits are subjected to N-myristoylation, which is an irreversible, co-translational attachment of 14-carbon myristrate to glycine at the $\mathrm{N}$-terminus through an amide bond, and/or palmitoylation, which is a reversible, post-translational attachment of 16 carbon palmitate to cysteine residues near the $\mathrm{N}$-terminus through thioester bonds. Both G $\alpha 12$ and 13 lack a glycine residue at the second site for myristoylation and thus are modified by only palmitoylation near their $\mathrm{N}$ termini [65-67]. Although palmitoylation has no clear consensus sequence, one site (C12) in G $\alpha 12$ [65] and two sites $(\mathrm{C} 14, \mathrm{C} 18)$ in $\mathrm{G} \alpha 13$ [66] have been defined as sites of palmitate incorporation using mutants in which serine replaces these cysteine residues.

It has been demonstrated that palmitoylation of $\mathrm{G} \alpha 13$ is critical for its association with the plasma membrane, translocation of its effector p115RhoGEF, and its ability to signal through RhoA [68]. It has also been reported that palmitoylation of $\mathrm{G} \alpha 12$ but not $\mathrm{G} \alpha 13$ is related to localization in lipid rafts [69]. A constitutively active mutant of $\mathrm{G} \alpha 12$ which cannot be palmitoylated inhibits its transforming activity in NIH-3T3 cells [65]. It is interest- ing to note that palmitoylation of another $\mathrm{G} \alpha$ subunit, G $\alpha$ z, decreases its affinity for Gz GAP and its rate of GTP hydrolysis. However, this may not be the case with G $\alpha 12 / 13$ [70].

Phosphorylation of $\mathrm{G} \alpha$ subunits is another important modification which regulates the amplitude and duration of $G$ protein signals. $G \alpha 12$, as well as $G \alpha z$, is a substrate for phoshporylation by protein kinase C (PKC) [7174]. In vitro, $G \alpha 12$ is phosphorylated by $P K C \alpha,-\delta,-\varepsilon$, and $-\zeta$, and approximately $1 \mathrm{~mol}$ of phosphate was incorporated per mol subunit with PKC $\alpha$ [72]. G $\alpha 12$ stably expressed in NIH-3T3 cells is phosphorylated following treatment of the cells with PMA (phorbol 12-myristate 13-acetate) [72], and endogenous G $\alpha 12$ in human platelets is phosphorylated in response to PMA, thrombin, and the thromboxane $A_{2}$ receptor agonist U46619 [75]. Although the phosphorylation site has not been mapped, the N-terminal 50 amino acid residues comprise one possible region [72]. It is possible that Ser38 corresponding to Ser16 defined in G $\alpha z$ may be the phosphorylation site. As to phosphorylation of $\mathrm{G} \alpha 13$, there is a discrepancy between in vitro and cell-based experiments. In vitro experiments demonstrate purified $\mathrm{G} \alpha 13$ is not a substrate for PKC $\alpha,-\delta,-\varepsilon$, and $-\zeta[72]$. However, studies with intact cells show that $\mathrm{G} \alpha 13$ in platelets is phosphorylated in response to PMA, and G $\alpha 13$ expressed in COS cells is effectively phosphorylated by $\mathrm{PKC} \beta,-\delta$, and $-\varepsilon$ [75]. This discrepancy might indicate that additional cellular factors are required for phosphorylation of $\mathrm{G} \alpha 13$ by PKC.

It has been demonstrated that phosphorylation blocks

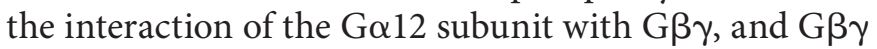
reciprocally blocks the phosphorylation of $\mathrm{G} \alpha 12$ by PKC [72]. This appears to be consistent with the fact that $G \beta \gamma$ binds the N-terminal helix of $\mathrm{G} \alpha$. G $\beta \gamma$ binding to the Nterminus of $\mathrm{G} \alpha$ may hinder PKC from approaching sterically, or reciprocally, phosphorylation of the N-terminus may block G $\beta \gamma$ binding. Furthermore, Kozasa and Gilman [37] demonstrated that the rate of GTP $\gamma S$ binding to phosphorylated $G \alpha 12$ is not inhibited by $G \beta \gamma$ whereas G $\beta \gamma$ inhibits GTP $\gamma S$ binding to non-phosphorylated Ga12. It is noteworthy that phosphorylation inhibits interaction of $G \alpha z$, another substrate for PKC, with the RGS protein RGSZ1, while it is unknown if phosphorylation of $\mathrm{G} \alpha 12$ produces a similar effect $[76,77]$. Interestingly, a genetic screening using Caenorhabditis elegans suggested that the novel calcium-independent $\mathrm{PKC} \theta / \delta$ is a potential downstream target of $\mathrm{G} \alpha 12$ [78]. Dhanasekaran et al. [79] have reported that $\mathrm{Na}^{+} / \mathrm{H}^{+}$exchange activity stimulated by $\mathrm{G} \alpha 12$ is lost after prolonged exposure of cells to PMA. Once activated upon binding of ligand to a 
GPCR, G $\alpha 12$ is phosphorylated by PKC, which could be activated downstream of G $\alpha 12$ itself. The phosphorylat-

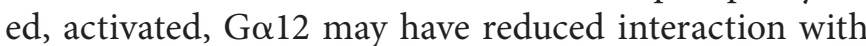
$\mathrm{G} \beta \gamma$, and be less susceptible to the GAP activity of RGS protein, prolonging the duration of signaling. The system would eventually desensitize because of a lack of reassociation between GDP-bound G $\alpha$ with $G \beta \gamma$ required for receptor-mediated reactivation. PKClikely attenuates the activity of $\mathrm{G} \alpha 12$ in a negative feedback loop, while the mechanism of PKC activation by G $\alpha 12$ is unknown. Tyrosine phosphorylation of $\mathrm{G} \alpha 12$ has not been reported.

\section{Regulation of Effectors by G12}

As mentioned above, $G \alpha 12$ and $G \alpha 13$ subunits directly activate RH-RhoGEFs to regulate the activity of the GTPase Rho [51-53, 55, 58]. p115RhoGEF was first identified as a direct downstream effector of the G12 subfamily 10 years ago. Since then, studies including the yeast two-hybrid system, have revealed more than 20 diverse proteins that directly interact with the G12 subfamily as well as RH-RhoGEFs; see recent reviews for further details [80, 81]. A well-established downstream effector of G12/13-mediated signaling is the monomeric GTPase RhoA, which is a regulator of a variety of intracellular processes including formation of actin stress fibers and assembly of focal adhesions, gene transcription, and control of cell growth $[78,82]$.

\section{Regulation of RH-RhoGEFs by G $\alpha 12 / 13$}

Biochemical evidence using reconstitution systems with purified proteins has clearly demonstrated that the GEF activity of p115RhoGEF and LARG can be directly stimulated by $\mathrm{G} \alpha 13$ [52, 58]. As mentioned above, $\mathrm{RH}-$ RhoGEFs combine GAP activity and effector activity into a single molecule. While it has been well demonstrated that p115RhoGEF and LARG serve as specific GAPs for G $\alpha 12 / 13$ through their RH domains, the molecular mechanism of RH-RhoGEF activation upon $\mathrm{G} \alpha 13$ binding remains unclear. Some recent studies have provided information about the interface between $\mathrm{G} \alpha 13$ and RH-RhoGEFs required for RH-RhoGEF activation.

A structural study using p115RhoGEF's RH domain

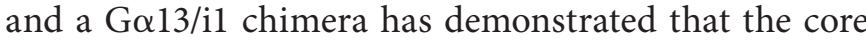
module of p115RhoGEF's RH domain binds to the region of $\mathrm{G} \alpha 13 / \mathrm{i} 1$ which is conventionally used for effector binding [54]. This result suggests roles for the RH domain in the stimulation of GEF activity by $\mathrm{G} \alpha 13$ in addition to GAP activity. Several studies have indicated that regions outside of RH domain of RH-RhoGEFs, particularly the $\mathrm{DH} / \mathrm{PH}$ domains, interact directly with activated $\mathrm{G} \alpha 13$
$[53,58,62]$. Wells et al. [53] demonstrated that $\mathrm{AlF}_{4}{ }^{-}$-activated G $\alpha 13$ was able to bind directly to a deletion mutant of p115RhoGEF consisting of the DH and PH domains, although it was unable to stimulate the GEF activity of the fragment in vitro. Interaction through multiple interfaces, including the $\mathrm{RH}$ domains and $\mathrm{DH} / \mathrm{PH}$ domains of RH-RhoGEFs, and G $\alpha 13$ might play an important role in stimulating GEF activity. Kinetic and thermodynamic analysis of the interaction between $\mathrm{G} \alpha 13$ and LARG using surface plasmon resonance has demonstrated that the simultaneous binding of the RH domain and $\mathrm{DH} / \mathrm{PH}$ domains with $\mathrm{G} \alpha 13$ facilitates formation of the high affinity active G $\alpha 13$-LARG complex [145].

In addition to analysis of the Go13-binding surfaces on RH-RhoGEFs, the surfaces of G $\alpha 13$ necessary for binding to RH-RhoGEFs have also been characterized.

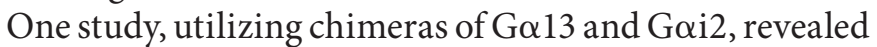
that not only the switch regions of $\mathrm{G} \alpha 13$, but also a large portion of the Ras-like domain of $\mathrm{G} \alpha 13$ are required for efficient Rho activation in cell-based assays [83]. Another

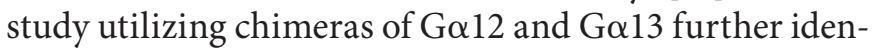
tified that the C-terminal 100 amino acid residues of G $\alpha 13$ are required for activation of the GEF activity of p115RhoGEF and LARG, whereas the N-terminal $\alpha$ helical and switch regions of $\mathrm{G} \alpha 12$ and $\mathrm{G} \alpha 13$ are responsible for their differential GAP responses to the $\mathrm{RH}$ domain [84]. This result demonstrates that p115RhoGEF and LARG interact with distinct surfaces on G $\alpha 13$ for GAP activity or GEF activity regulation. Furthermore, we have demonstrated that the interaction of G $\alpha 13$ with LARG through the $\mathrm{RH}$ domain (a GAP interface) and the $\mathrm{DH} /$ $\mathrm{PH}$ domains (an effector interface) could coordinate together to stimulate the RhoGEF activity of LARG [145]. In summary, the spatial and kinetic connection of GAP and GEF activities within RH-RhoGEFs may help to regulate the amplification of $G$ protein signaling, provide higher temporal resolution of the response, and increase the specificity of the signal output. Since G $\alpha 12 / 13$ have characteristically slow rates of nucleotide exchange and GTP hydrolysis, this mechanism could be a rational system for G $\alpha 12 / 13$ signaling to regulate multiple important cellular functions with fast responses as well as long-term processes.

On the other hand, binding of the activated G $\alpha 12$ does not activate the GEF activity of either p115RhoGEF or LARG in vitro. LARG activation requires not only binding to activated $\mathrm{G} \alpha 12$ but also phosphorylation by a nonreceptor tyrosine kinase $[52,58]$. 
Phosphorylation

One mechanism regulating $\mathrm{RH}-\mathrm{RhoGEF}$ activity is post-translational modification in the form of phosphorylation. Chikumi et al. [85] have demonstrated that the non-receptor tyrosine kinase FAK (focal adhesion kinase) phosphorylates both LARG and PDZ-RhoGEF, but not p115RhoGEF. By measuring the Rho activity of HEK293 cells overexpressing FAK and PDZ-RhoGEF, they have concluded that FAK enhances RhoGEF activity even in the absence of $G \alpha 12$ or G $\alpha 13$. They also observed

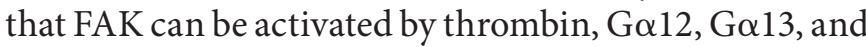
G $\alpha \mathrm{q}$ through both Rho-dependent and -independent mechanisms, and proposed the existence of positive feedback regulation between Rho and FAK [85]. Another study using reconstitution and cell-based assays has demonstrated that G $\alpha 12$ can stimulate the RhoGEF activity of tyrosine-phosphorylated LARG, but not non-phosphorylated LARG [52]. The direct phosphorylation of LARG by a non-receptor tyrosine kinase, Tec, in vitro greatly enhances the RhoGEF activity of LARG in response to $\mathrm{G} \alpha 12$, while it does not affect its basal RhoGEF

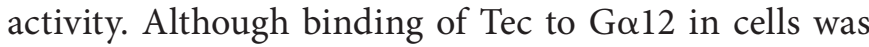
also demonstrated, the mechanism by which Tec is phosphorylated downstream of $\mathrm{G} \alpha 12$ remains unclear. It is interesting to note that thrombin, which can activate the Go12/13 pathway, can also activate Tec [86] and that $\mathrm{G} \alpha 12$ promotes the kinase activity of Bruton's tyrosine kinase (BTK), another member of the Tec family [87]. Furthermore, overexpression of G $\alpha 12$ and G $\alpha 13$ stimulates auto- and transphosphorylation of Tec in NIH-3T3 cells [88]. One possibility is that activated G $\alpha 12$ may recruit Tec to LARG and facilitate its phosphorylation.

The role of tyrosine kinases involved in the G $\alpha 12 / 13$ Rho pathway is controversial. In vitro, the RhoGEF activity of non-phosphorylated LARG was stimulated by G $\alpha 13$ but not $G \alpha 12$, suggesting that the Go13-LARG-Rho pathway does not require tyrosine kinases. However, in cell-based assays, the presence of Tec further potentiates the RhoGEF activity of LARG stimulated by G $\alpha 13$ in NIH-3T3 or HeLa cells $[52,88]$. In the context of cells, G $\alpha 13$ and tyrosine kinases cooperatively and efficiently activate Rho. In contrast to the study by Suzuki et al., early studies of $\mathrm{G} \alpha 12 / 13$-mediated cytoskeletal reorganization suggested that tyrosine kinases might play a role in regulating Rho activation downstream of $\mathrm{G} \alpha 13$, but

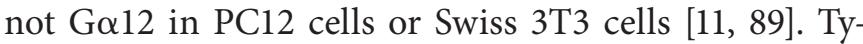
rosine phosphorylation of PDZ-RhoGEF and LARG is an important post-translational modification regulating RhoGEF activity downstream of G $\alpha 12$ and $G \alpha 13$.
C-Terminal Regions and Oligomerization

Several studies have reported that RH-RhoGEFs oligomerize via their C-terminal regions [90-92]. It has been shown that RH-RhoGEF deletion mutants lacking their C-termini have an increased ability to stimulate Rho activation as compared to the full-length protein, and that the deletion of the $\mathrm{C}$-terminal region alone is sufficient to increase the RhoGEF's transforming potential in cells [90, 93]. These results suggest that the RH-RhoGEF's activity may be negatively regulated in vivo through the $\mathrm{C}$-terminus itself or by interaction of regulatory factors with this region. First, to identify regulatory proteins interacting with the C-terminus of RH-RhoGEFs, Eisenhaure et al. [91] utilized yeast two-hybrid screening with the C-terminus of the murine ortholog of p115RhoGEF, Lsc. Surprisingly, the only protein identified was a C-terminal fragment of Lsc itself, suggesting that it homo-oligomerizes via its $\mathrm{C}$-terminal region. Using mutagenesis experiments, they further showed that homo-oligomerization and negative regulation of Lsc activity are distinct functions of its C-terminus. Disruption of a putative coiled-coil domain within the $\mathrm{C}$-terminus impairs oligomerization, but does not result in enhanced Rho activation in cells. A subsequent study confirmed the homo-oligomerization of p115RhoGEF, LARG, and PDZ-RhoGEF via their C-terminal regions by co-immunoprecipitation using cells overexpressing the RH-RhoGEFs [90] (fig. 2). LARG and PDZ-RhoGEF have also been shown to possibly form hetero-oligomers with each other, but not with p115RhoGEF [90].

Interestingly, deletion of the C-terminus of PDZ-RhoGEF or p115RhoGEF does not affect or even reduces the RhoGEF activity in vitro, while it dramatically enhances the RhoGEF activity in cells $[90,93]$. This discrepancy suggests that ancillary factors in cellular milieus might release the inhibition of the RH-RhoGEF's activity through the C-terminal region. A possible mechanism is that an activating protein releases the inhibition through the $\mathrm{C}$-terminus to induce the active conformation of $\mathrm{RH}$ RhoGEFs. One potential activating protein might be the active form of $\mathrm{G} \alpha 13$, since activation-dependent binding between the C-terminus of LARG and G $\alpha 13$ has been observed [145]. Interestingly, the Rho effector Dial also binds to the C-terminus of LARG to potentiate its GEF activity, and its activation constitutes a positive feedback loop between LARG, RhoA, and Dial [94]. Another mechanism is post-translational modification at the Cterminal region. It is interesting to note that PDZ-RhoGEF is tyrosine-phosphorylated by FAK at its C-terminus [85]. 
A recent study has suggested that oligomerization of overexpressed LARG may regulate its intracellular localization. Oligomerization functions to prevent nucleocytoplasmic shuttling and to retain LARG in the cytoplasm, while the mechanism for regulation of LARG oligomerization and the function of LARG localized in the nucleus are unknown [92]. Further study is required to understand the physiological significance of oligomerization of endogenous RH-RhoGEFs.

\section{Subcellular Localization}

Translocation of RH-RhoGEFs to the plasma membrane where their target, Rho, is enriched seems to be another important mechanism for regulating RhoGEF activity. Intracellular localization of p115RhoGEF has been intensively studied. However, it should be noted that the distribution of endogenous and overexpressed $\mathrm{RH}$ RhoGEFs might differ. Indeed, it has been demonstrated by subcellular fractionation of NIH-3T3 cells that endogenous p115RhoGEF is found mainly in the cytosolic fraction with approximately $10-20 \%$ of the protein localized to the membrane fraction, while overexpressed p115RhoGEF was distributed abundantly between both the membrane and cytosolic fractions [93]. Both immunocytochemical and cellular fractionation analyses have demonstrated that co-expression of the constitutively active form of $\mathrm{G} \alpha 12$ as well as $\mathrm{G} \alpha 13$ or stimulation of the thromboxane $A_{2}$ receptor, which couples with $G \alpha 12 / 13$, induces redistribution of endogenous and overexpressed p115RhoGEF to the plasma membrane in HEK293 cells $[68,95]$. Using overexpressed p115RhoGEF deletion mutants, these studies have identified the $\mathrm{RH}$ domain and the PH domain as essential for targeting of p115RhoGEF to the plasma membrane by $\mathrm{G} \alpha 13$. However, the RhoGEF activity of these mutants in the presence of $G \alpha 13$ was not tested in cells. Furthermore, Bhattacharyya and Wedegaertner [64] tested the role of the acidic-rich region $\mathrm{N}$ terminal to the RGS domain of p115RhoGEF in G $\alpha 13$ dependent plasma membrane recruitment in cell-based assays, based on the finding that this region is important

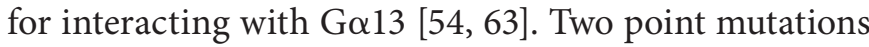
in this region, Glu27Ala and Glu29Ala, impair the ability of p115RhoGEF to bind to G $\alpha 13$ but did not affect its ability to localize to the plasma membrane [64].

Compared with p115RhoGEF, the mechanisms for regulating the subcellular distribution of PDZ-RhoGEF and LARG are less well understood. One immunohistochemistry study using polyclonal antibodies has shown that $G \alpha 12, G \alpha 13$, PDZ-RhoGEF and LARG proteins are distributed widely in the mouse nervous system, but lo- calize to distinct morphological compartments within neurons. While LARG and G $\alpha 12$ were mainly found in the somata of neurons, PDZ-RhoGEF and G $\alpha 13$ were predominantly localized in the neuropil of central neurons [96]. An immunocytochemical analysis has demonstrated that endogenous PDZ-RhoGEF in Neuro2a cells is localized in the nucleus, cell body, and neurites, and upon stimulation of the LPA receptor, which is coupled to G $\alpha 12 / 13$, PDZ-RhoGEF translocates to the tips of neurites, where Rho is enriched and cortical actin reorganization is induced [97]. Furthermore, analyses by Togashi et al. [97] revealed that a proline-rich motif C-terminally adjacent to $\mathrm{DH} / \mathrm{PH}$ domains is essential for plasma membrane localization of PDZ-RhoGEF and cortical actin reorganization followed by cell rounding. However, the effects of mutating in this region on the interaction with $G \alpha 13$ was not investigated. It has also been reported that PDZ-RhoGEF overexpressed in HEK293T, COS7, and Neuro2a cells is partially localized at or near the plasma membrane and co-localizes with cortical actin [98]. Immunoprecipitation and F-actin co-sedimentation assays demonstrated that PDZ-RhoGEF binds to actin. Mutants that fail to interact with the actin cytoskeleton display enhanced Rho activation compared with wild type PDZ-RhoGEF. Togashi et al. [97] also have reported that PDZ-RhoGEF appears to co-localize with microtubules. It has been proposed that not only $\mathrm{G} \alpha 12 / 13$ but also its downstream target myosin II may be involved in regulating PDZ-RhoGEF localization and activation, although the biochemical mechanism remains unknown [99]. These results imply that the interaction with actin, myosin, and microtubules might regulate PDZ-RhoGEF signaling.

In contrast to PDZ-RhoGEF, endogenous LARG in COS7 cells exhibits a predominantly cytoplasmic distribution [92]. In MDCKII cells, endogenous LARG was reported to be localized at the lateral membranes and slightly in the cytoplasm [100]. Overexpressed LARG seems to be distributed throughout the cytoplasm and does not co-localize with actin [98].

The co-localization of PDZ-RhoGEF and LARG with receptors at the plasma membrane via their PDZ domains is clearly distinct from p115RhoGEF, which does not contain a PDZ domain (fig. 1, 2). Several studies using biochemical and cell-based analyses have demonstrated that plexin $\mathrm{B} 1$, which is a transmembrane receptor that mediates the repulsive cues of semaphorin $4 \mathrm{D}$ to initiate collapse of neurite growth cones in mammals, directly interacts through its C-terminus with the PDZ domains of PDZ-RhoGEF and LARG [101-104]. Taya et al. [100] have 


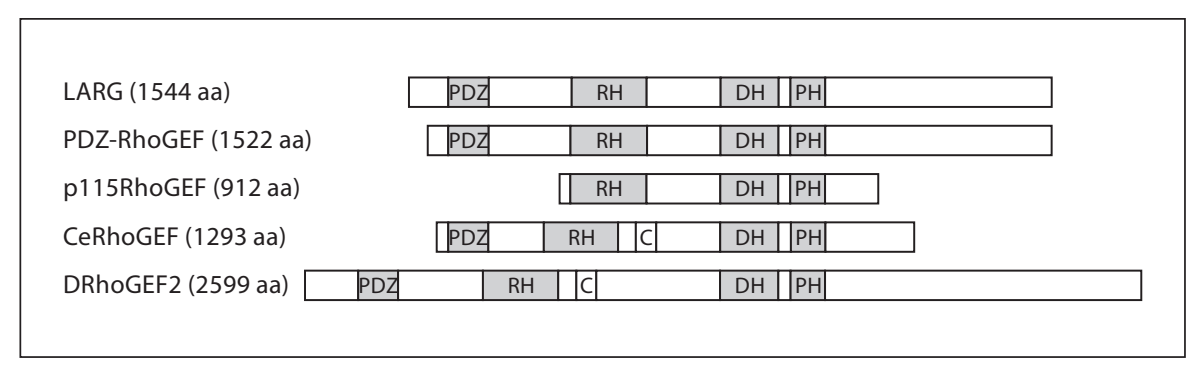

Fig. 2. A schematic representation of domain structures of RHRhoGEFs. LARG, PDZ-RhoGEF and p115RhoGEF are the three known human RH-RhoGEFs. All RH-RhoGEFs contain RH domains followed by tandem $\mathrm{DH} / \mathrm{PH}$ domains. The N-terminal region of PDZ-RhoGEF and LARG each contain a PDZ domain. For comparison, CeRhoGEF and DRhoGEF2, RGS-RhoGEFs from $C$. elegans and D. melanogaster, respectively, are depicted as well. Unlike human RGS-RhoGEFs, CeRhoGEF and DRhoGEF2 each contain one C1 homology domain. Domains: RH = RGS homology domain; $\mathrm{DH}=\mathrm{Dbl}$ homology; $\mathrm{PH}=$ pleckstrin homology; PDZ = PSD-95/SA90-Discs-large-ZO-1; C = C1 homology domain. reported that the C-terminus of non-phosphorylated insulin-like growth factor-1 (IGF-1) receptor also directly interacts with LARG and that IGF-1 stimulation in MDCKII cells induces Rho activation.

\section{Crosstalk between G12/13-Mediated Signaling and Other Signaling Pathways}

The G12/13-mediated signaling pathway engages in crosstalk with other pathways at various levels such as GPCRs (described above), G proteins, and downstream effectors (fig. 1). At the $\mathrm{G}$ protein level, G $\alpha 12$ and $\mathrm{G} \alpha 13$ interact directly and in an activation-dependent manner with the cytoplasmic tails of cadherins $[105,106]$. Binding of activated G $\alpha 12$ to the cytoplasmic tail of E-cadherin triggers the release of the transcriptional activator $\beta$-catenin attenuates the extracellular adhesive function of E-cadherin, and promotes cell migration $[105,106]$. Go12 may integrate the LARG-Rho signaling pathway controlling cytoskeletal rearrangement and the cadherin$\beta$-catenin signaling pathway regulating cell-cell adhesion to govern cell migration in response to extracellular stimulation. It has also been reported that $\mathrm{G} \alpha 12$ interacts with and activates a member of the Tec family of non-receptor tyrosine kinases, BTK, while G $\alpha 13$ binds and stimulates PYK2, another non-receptor tyrosine kinase $[87,107]$.

RH-RhoGEFs are also capable of interacting with various other cellular proteins. In particular, PDZ-RhoGEF and LARG are well known to interact with multiple cell surface receptors through their PDZ domain as previously described. One of the binding partners for the PDZ domain is plexin B1. Multiple studies have demonstrated that binding of the C-terminal PDZ-binding motif of plexin B1 with both PDZ-RhoGEF and LARG activates RhoA and promotes growth cone collapse [101-104]. This pathway is also known to be involved in angiogenesis [108]. Additionally, the direct binding of the C-terminus of the IGF-1 receptor to LARG induces RhoA activation [100]. It is noteworthy that in these two cases, binding of plexin B or IGF-1 receptor activates the GEF activity of RH-RhoGEFs independently of G $\alpha 12 / 13$ activation. Direct interaction between the PDZ domain of LARG and CD44 in human head and neck squamous carcinoma cells has also been reported [109]. This CD44-LARG complex interacts with the EGF receptor and activates the EGFR receptor kinase. The C-terminus of the LPA receptor also interacts with the PDZ domains of LARG and PDZ-RhoGEF [110]. p115RhoGEF has been reported to interact with the C-terminus of HIV-1's transmembrane protein gp41 [111]. This interaction inhibits the ability of p115RhoGEF to initiate Rho-dependent stress fiber formation and gene transcription. Interestingly, mutations in gp41 that block the interaction with p115RhoGEF inhibit the ability of the HIV-1 virus to produce infectious particles in certain cell types. This finding suggests that the interaction between gp41 and p115RhoGEF modulates the ability of the virus to replicate. As described above, the Rho effector Dial binds to the C-terminus of LARG, stimulates its GEF activity, and may constitute a positive feedback loop between LARG, RhoA, and Dial [94].

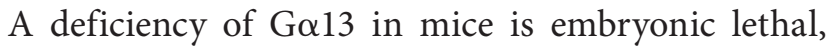
while mice lacking $G \alpha 12$ develop normally and do not exhibit any overt morphological or behavioral defects. This fact clearly shows that $G \alpha 13$ and $G \alpha 12$ mediate distinct signaling pathways. The studies of intercrosses of 


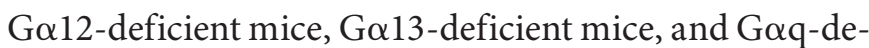
ficient mice indicate that the Go12-mediated signaling pathway functionally interacts not only with the G $\alpha 13$ but also with the Gaq-mediated signaling systems [28]. Coordinated action from the two signals is known at the level of transcriptional factors [32] and protein kinases such as protein kinase D and PYK2 [36, 112]. The signals from $\mathrm{G} \alpha 12 / 13$ and $\mathrm{G} \alpha \mathrm{q}$ have been known to converge on Rho, which is a target for $\mathrm{G} \alpha 12 / 13[35,113,114]$. Recently, p63RhoGEF, together with the related Dbl-family member Trio, has been identified as a direct effector of $\mathrm{G} \alpha \mathrm{q}$ and a guanine nucleotide exchange factor for RhoA, and the crystal structure of the G $\alpha$ q-p63RhoGEF-RhoA complex has also been determined [31,33]. The crosstalk

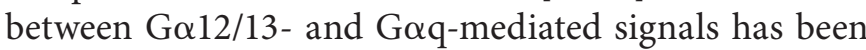
noted for smooth muscle contraction [30] and platelet activation [115].

\section{Dissection of G12/13-Mediated Signaling Pathways}

Evoked by Specific G $\alpha$-Effector Interactions

Accumulating evidence supports the idea that GPCR signals are amplified and integrated into the intracellular signaling network at the level of $\mathrm{G}$ proteins [116]. The $\mathrm{G} \alpha$ subunit acts as the core of the signaling complex at the membrane, which is formed through transient proteinprotein interactions between multiple signaling components.

Recently, some groups have tried to regulate the specific signal induced by the $\mathrm{G} \alpha$-effector interaction. Using substitution mutants of $\mathrm{G} \alpha 12$ at the specific interface for the G $\alpha 12$-effector interaction, Meigs et al. [117] have successfully identified a variant of G $\alpha 12$ that is selectively uncoupled from one signaling pathway while retaining signaling capacity through a separate pathway: it has impaired binding to $\mathrm{RH}-\mathrm{RhoGEFs}$ and is unable to activate Rho, but retains coupling to the effector cadherin and the ability to trigger $\beta$-catenin release from the cytoplasmic domain of cadherin. A study using small interfering RNAs to eliminate specific RH-RhoGEF expression in kidney and prostate cells has demonstrated that specific G12-coupled receptors require specific RH-RhoGEFs for Rho activation [118]. Thrombin-mediated stimulation of Rho requires LARG, while the LPA-stimulated Rho response requires PDZ-RhoGEF. These efforts to evaluate the specific signals mediated by G12/13 could lead to development of specific modulators for biological responses induced by divergent effectors, and eventually drugs with fewer side effects.

\section{Physiological Function and Pathophysiological Significance of G12/13-Mediated Signaling Pathways}

Advances in animal studies such as conditional knockout mice and genetic analysis in Caenorhabditis elegans and Drosophila melanogaster have imparted new biological significance to the G12 subfamily. Conservation of a Ga12/13-RH-RhoGEF-Rho signaling pathway through the course of evolution from the model organisms C. elegans and $D$. melanogaster to mammals is supported by genetic evidence. In a mutational screen to identify Rho signaling pathway components in Drosophila, Barrett et al. [9] identified the DRhoGEF2 gene, which encodes a protein containing the tandem $\mathrm{DH} / \mathrm{PH}$ domains characteristic of RhoGEFs, as an upstream Rhol activator. Embryos lacking functional DRhoGEF2 show similar defects in the cell shape changes associated with gastrulation to embryos without functional Concertina, the single Drosophila $\mathrm{G} \alpha 12 / 13$ ortholog, suggesting that Concertina may propagate signals from an upstream ligand to Rhol via DRhoGEF2 $[9,10]$. Subsequently, the N-terminus of DRhoGEF2 was shown to have sequence homology with other putative RhoGEFs containing $\mathrm{RH}$ domains in their N-terminus [51]. Another study has demonstrated that in C. elegans, GPA-12, the ortholog of Go12, and a RH-RhoGEF, CeRhoGEF, can interact in an activation-dependent manner and are co-expressed in some ventral cord motor neurons [119]. In the same study, silencing of either GPA-12 or CeRhoGEF using RNA interference (RNAi) results in a similar phenotype, namely defects in egg laying and embryonic lethality, further suggesting these two proteins function in the same pathway. Additional studies in C. elegans support the notion that one of the pathways acting upstream of Rhol in acetylcholine-releasing motor neurons, where Rhol stimulates the release of acetylcholine [120], depends on GPA12 , which acts via the single RH-RhoGEF ortholog, RHGF-1 [16]. It has been reported that Gq also acts via the UNC-73 RhoGEF, an ortholog of mammalian Trio, to increase Rho activity in neurons [121].

The first identified $G \alpha 12 / 13$ function was the ability to induce oncogenic transformation [12-15]. Since then, many studies of the biological functions of G12/13 have concentrated on their roles in cell proliferation, cell migration, and morphological changes. Accumulating evidence indicates that the G12/13-mediated signaling pathway is involved in a variety of physiological and pathophysiological processes as mentioned in the introduction.

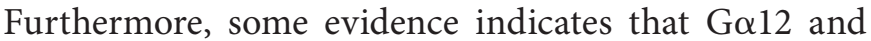


G $\alpha 13$ have partially overlapping but distinct cellular and biological functions $[28,29]$, and that G12 or G13-mediated signals crosstalk with those from other $G$ proteins, especially $\mathrm{Gq}$ to produce a biological response $[3,11,28$, $30-36]$.

\section{Cell Proliferation and Transformation - Neoplastic Disorders}

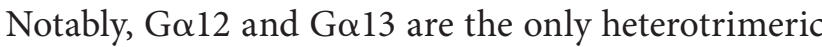
$\mathrm{G} \alpha$ subunits that have potent transforming capabilities when overexpressed as the wild-type forms. These tumorigenic and cell-proliferating effects of G12/13 seem to be mainly mediated by RhoA activation. Martin et al. [27] have demonstrated that overexpression of the thrombin protease-activated receptor-1 (PAR-1) promotes transformation and growth in NIH-3T3 cells through Go12/13. PAR-1 stimulates the activity of the serum response factor and NF- $\kappa$ B transcription factors, which are also effectors of RhoA. Furthermore, PAR-1 transforming activity is partially blocked by co-expression of dominant negative RhoA. Other studies also suggest that GPCRs upstream of $\mathrm{G} \alpha 12$ and $\mathrm{G} \alpha 13$ may promote tumorigenesis and tumor cell growth $[25,32,122,123]$. Indeed, recent studies demonstrated that $\mathrm{G} \alpha 12$ protein levels are upregulated in human breast or prostate adenocarcinoma tissues $[22,23]$. Interestingly, in contrast to the previous

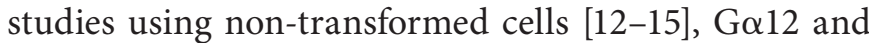
G $\alpha 13$ did not promote, and in some cases even inhibited, in vitro or in vivo proliferation of human breast or prostate cancer cell lines $[22,23]$. Therefore, G $\alpha 12$ and $G \alpha 13$ may be important for promoting normal cell proliferation. In addition, it has been reported that $\mathrm{G} \alpha 13$-induced transformation uses a Rho-independent pathway via radixin, a member of the ERM family of proteins [124, 125].

It is noteworthy that unlike Ras, activating mutations in Rho have not been found in human cancers [126-128]. On the other hand, the regulators of Rho activation, RhoGEFs have been isolated in screens for transforming genes. LARG was one of the very few RhoGEFs that have been found mutated in human cancers. LARG was originally identified as a novel protein fused to the MLL (mixed lineage leukemia) gene in a patient with acute myeloid leukemia [21]. It is interesting that in the MLLLARG fusion, not only the $\mathrm{DH} / \mathrm{PH}$ domains responsible for Rho activation but also the RH domain and a nuclear localization signal are retained. The MLL-LARG rearrangement is expressed as an in-frame fusion from the MLL promotor. A study has indeed shown that LARG is abundant in mouse hematopoietic stem cells [129]. Fur- thermore, a recent analysis of bone marrow samples from patients with the preleukemic disorder Shwachman-Diamond syndrome demonstrated that in these patients LARG expression is dramatically increased [130]. However, further studies will be necessary to confirm the roles of LARG and MLL-LARG fusion protein in leukemic disease.

\section{Cell Morphology and Motility - Failure in \\ Gastrulation and Tumor Cell Invasion}

Some aspects of the biological effects mediated by the G $\alpha 12 / 13$ signaling pathway are contributed by the capability of their downstream effector, RhoA, to regulate cell morphology and motility. RhoA induces the assembly of contractile actin and myosin filaments (stress fibers), and is involved in cell contraction as well as in moving the body and tail of the cell behind the leading edge [128, 131, 132]. Cadherin, acting downstream of G $\alpha 12$, also affects cell migration independently of Rho activation [105]. Gastrulation, which is regulated by the $\mathrm{G} \alpha 12 / 13$ ortholog and a RH-RhoGEF in D. melanogaster $[9,10]$, and tumor cell invasion, are related to these shape changes and movement.

Tumor Cell Invasion

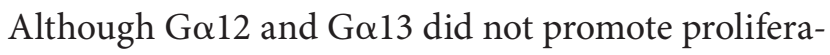
tion of human breast or prostate cancer cell lines, they promoted invasion by both types of cancer cells in vitro $[22,23]$. Mouse mammary carcinoma cells implanted in the mammary fat pad of a mouse, which grow and metastasize in a manner similar to that of human breast cancer, has demonstrated that inhibition of $\mathrm{G} \alpha 12 / 13$ signaling by stable expression of the RH domain of p115RhoGEF in carcinoma cells reduced the rate of metastatic dissemination [22]. These studies suggest that Rho activation through $\mathrm{G} \alpha 12 / 13$ signaling is critical for promoting invasion. However, when seeded directly into the bloodstream, inhibition of G12/13 signaling by the RH domain had no effect on the ability of the cells to metastasize. Signaling via the G12-Rho pathway may coordinate with signals from cadherin, which influences cell-cell contacts, to promote invasion away from the primary tumor. However, it is possible that invasion stimulated by $\mathrm{G} \alpha 12$ and $\mathrm{G} \alpha 13$ may be cell type-specific [80].

\section{The Cardiovascular System - Heart and Vascular}

Disease and Angiogenesis

A deficiency of $\mathrm{G} \alpha 13$ in mice impairs the development of the vascular system and is embryonic lethal [6]. Embryonic fibroblasts cultured from these mice show im- 
paired motility in response to thrombin and LPA. Although vasculogenic blood vessel formation through the differentiation of progenitor cells into endothelial cells was not affected, angiogenesis, which includes sprouting, growth, migration and remodeling of existing endothelial cells, was severely disturbed $[6,29]$. Endothelial-specific $\mathrm{G} \alpha 13$ knockout embryos also showed a similar phenotype to that of $\mathrm{G} \alpha 13$ null animals. However, restoration of G $\alpha 13$ expression in endothelial cells in $\mathrm{G} \alpha 13$ conventional knockouts fails to completely rescue the phenotype, suggesting that $\mathrm{G} \alpha 13$ expression in other cell types is necessary during embryonic development [7]. In contrast to the phenotype observed in G $\alpha 13$ null mice, mice lacking G $\alpha 12$ develop normally and do not exhibit any obvious morphological or behavioral defects. A double knockout of $\mathrm{G} \alpha 12$ and $\mathrm{G} \alpha 13$ produces developmental defects in the headfold, somites, and neural tube and these embryos arrest earlier than G $\alpha 13$ null embryos, suggesting that the function of G $\alpha 12$ is not completely redundant to that of $\mathrm{G} \alpha 13$ during embryonic development [28]. In addition, a study suggests that semaphorin 4D/plexin B1-mediated angiogenic responses require Rho-mediated signaling via PDZ-RhoGEF or LARG [108]. As described above, binding of the C-terminal PDZ-binding motif of plexin B with both PDZ-RhoGEF and LARG activates RhoA.

\section{Platelets}

Studies using mice lacking $\mathrm{G} \alpha 13$ in platelets revealed that this $\alpha$ subunit is involved in normal hemostasis and thrombosis. Platelets lacking $G \alpha 13$, but not $G \alpha 12$, have impaired shape changes and aggregation in response to multiple platelet activators in vitro, and fail to form stable thrombi ex vivo. The mice exhibit a large increase in tailbleeding times [5].

\section{Smooth Muscle}

It is believed that upon binding with vasoconstrictors, receptors coupling to both $\mathrm{Gq} / 11$ and $\mathrm{G} 12 / 13$ stimulate phosphorylation of myosin light chain (MLC) via the $\mathrm{Ca}^{2+} / \mathrm{MLC}$ kinase- and Rho/Rho kinase-mediated signaling pathways, respectively, to regulate vascular smooth muscle tone [30]. Recently, mice with conditional G $\alpha 12 / 13$ double deficiencies in smooth muscle cells have been developed [24]. Aortic segments from these mice show impaired contractile responses to the vasoconstrictors angiotensin II, thromboxane $\mathrm{A}_{2}$, and endothelin I. Furthermore, these mice are almost completely protected from salt-induced hypertension, while their basal blood pressure is unaffected. Similar phenotypes were observed in mice lacking LARG in smooth muscle cells. These find-

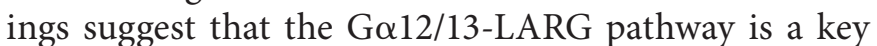
regulator of vascular smooth muscle tone in the context of hypertension.

\section{Heart}

In cardiomyocytes, c-Jun $\mathrm{NH}_{2}$-terminal kinase (JNK) activation triggers hypertrophic responses [133]. It has been reported that $\alpha_{1}$-adrenergic receptor-induced hypertrophic responses are mediated in part by a $G \alpha 12 / 13$ Rho-JNK pathway, and in part by a Gq/11-JNK pathway that is Rho independent [134].

\section{The Immune System}

Several studies have suggested that G $\alpha 12 / 13$ signaling pathways play a pivotal role in regulating chemotaxis. Defects in Lsc (p115RhoGEF) null mice are primarily found in the immune system, which is reasonable as p115RhoGEF/Lsc is strongly expressed in hematopoietic tissue $[4,135-138]$. These mice have reduced T-cell populations in their spleen and lymph nodes, as well as reduced numbers of marginal zone B cells in the spleen. Lsc null mice also display defects in lymphocyte migration, pseudopod formation, integrin-mediated adhesion and immune responses, suggesting that it is required for normal B- and T-lymphocyte function $[4,139]$.

\section{The Neuronal System - Neurologic Disorders}

The Rho family, which includes Rho, Rac, and Cdc42, has an important role in regulating actin cytoskeletal dynamics and has been implicated in growth cone guidance [140]. Rac and Cdc42 activation promote the formation of cell protrusions and adhesions at the leading edge, whereas Rho activation is thought to induce retraction through actinomyosin contraction at the trailing edge. It has been demonstrated that in neuronal cell lines, G $\alpha 12$ and Ga13 specifically activate RhoA and cause Rho-dependent neurite retraction [11, 17]. Katoh et al. also have shown that $\mathrm{G} \alpha \mathrm{q}$ collaborates with $\mathrm{G} \alpha 12$ and $\mathrm{G} \alpha 13$ to regulate neurite retraction in a Rho activation-dependent manner. Furthermore, LPA and S1P have been shown to induce neurite retraction through GPCR and RhoA activation $[17,141]$.

Recently, Moers et al. [18] have developed mice with conditional ablation of the genes encoding both $\mathrm{G} \alpha 12$ and $\mathrm{G} \alpha 13$ in the nervous system. They crossed Ga12-deficient mice which were homozygous for a floxed $\mathrm{G} \alpha 13$ allele with a transgenic mouse line expressing Cre under the control of the neuron-specific enhancer of the nestin promoter and the NEX promotor, which restricts recom- 
bination to neuronal and glial precursor cells starting at E10.5 and to principal neurons of the forebrain excluding glial cells and interneurons, respectively. The mice showed neuronal ectopia of cerebral and cerebellar cortices due to overmigration of cortical plate neurons and cerebellar Purkinje cells, respectively. Embryonic cortical neurons and Purkinje cells isolated from these mice were unable to retract their neurites in response to LPA and S1P. This result indicates that the G $\alpha 12 / G \alpha 13$ signaling pathway is involved in the proper positioning of migrating cortical neurons.

The semaphorin4/plexin B signaling pathway also may affect axon guidance through the G12/13-RH-RhoGEF-RhoA signaling pathway. Sema4D stimulates RhoA activation through PDZRhoGEF and LARG as described above, while plexin B may suppress Rac function by competing with other Rac downstream targets, such as p21activated kinase (PAK) [142]. A study suggests that the G12/13-RH-RhoGEF-RhoA signaling pathway is involved in Sonic hedgehog/Smoothened-mediated cellular responses, including stimulation of target gene promoters and inhibition of neurite outgrowth in neuroblastoma cells [143]. In addition, a study has demonstrated that morphological changes can also occur in glial cells in addition to neurons in response to $\mathrm{G} \alpha 12 / \mathrm{G} \alpha 13$ activa- tion [144]. This study also suggests that stimulation of the thromboxane $\mathrm{A}_{2}$ receptor causes astrocyte proliferation mainly through a $\mathrm{G} \alpha 12 / \mathrm{G} \alpha 13$ signaling pathway.

\section{Future Directions}

In this review, we have focused on studies highlighting the physiological significance of G12/13-mediated signaling and the regulatory mechanisms controlling this pathway. As focus on G12/13-mediated signaling has increased, it is becoming clear that these pathways participate in a variety of disease processes. In order to develop drugs to specifically regulate biological functions induced by G12/13mediated signaling, it is essential to define the interfaces for protein-protein interactions in this signaling system. In the coming years, it will be important to analyze the molecular dynamics of these protein-protein interactions in conjunction with determining the structures of these complexes using high resolution X-ray crystallography.

\section{Acknowledgement}

This work was supported by a grant for Translational Systems Biology and Medicine Initiative (TSBMI) from the Ministry of Education, Culture, Sports, Science and Technology of Japan and NIH grant GM61454.

\section{References}

1 Simon MI, Strathmann MP, Gautam N: Diversity of $G$ proteins in signal transduction. Science 1991;252:802-808.

2 Strathmann MP, Simon MI: G alpha 12 and $G$ alpha 13 subunits define a fourth class of $\mathrm{G}$ protein alpha subunits. Proc Natl Acad Sci USA 1991;88:5582-5586.

$\checkmark 3$ Althoefer H, Eversole-Cire P, Simon MI: Constitutively active Galphaq and Galpha13 trigger apoptosis through different pathways. J Biol Chem 1997;272:24380-24386.

4 Girkontaite I, Missy K, Sakk V, Harenberg A, Tedford K, Potzel T, Pfeffer K, Fischer KD: $\mathrm{Lsc}$ is required for marginal zone $\mathrm{B}$ cells, regulation of lymphocyte motility and immune responses. Nat Immunol 2001;2:855-862.

$\checkmark 5$ Moers A, Nieswandt B, Massberg S, Wettschureck N, Gruner S, Konrad I, Schulte V, Aktas B, Gratacap MP, Simon MI, Gawaz M, Offermanns S: G13 is an essential mediator of platelet activation in hemostasis and thrombosis. Nat Med 2003;9:1418-1422.

-6 Offermanns S, Mancino V, Revel JP, Simon MI: Vascular system defects and impaired cell chemokinesis as a result of Galpha13 deficiency. Science 1997;275:533-536.
Ruppel KM, Willison D, Kataoka H, Wang A, Zheng YW, Cornelissen I, Yin L, Xu SM, Coughlin SR: Essential role for Galpha13 in endothelial cells during embryonic development. Proc Natl Acad Sci USA 2005;102: 8281-8286.

-8 Xu J, Wang F, Van Keymeulen A, Herzmark P, Straight A, Kelly K, Takuwa Y, Sugimoto N, Mitchison T, Bourne HR: Divergent signals and cytoskeletal assemblies regulate self-organizing polarity in neutrophils. Cell 2003;114:201-214

-9 Barrett K, Leptin M, Settleman J: The Rho GTPase and a putative RhoGEF mediate a signaling pathway for the cell shape changes in Drosophila gastrulation. Cell 1997;91: 905-915.

10 Parks S, Wieschaus E: The Drosophila gastrulation gene concertina encodes a $\mathrm{G}$ alphalike protein. Cell 1991;64:447-458.

$\checkmark 11$ Katoh H, Aoki J, Yamaguchi Y, Kitano Y, Ichikawa A, Negishi M: Constitutively active Galpha12, Galpha13, and Galphaq induce Rho-dependent neurite retraction through different signaling pathways. J Biol Chem 1998;273:28700-28707.
12 Chan AM, Fleming TP, McGovern ES, Chedid M, Miki T, Aaronson SA: Expression CDNA cloning of a transforming gene encoding the wild-type $\mathrm{G}$ alpha 12 gene product. Mol Cell Biol 1993;13:762-768.

13 Jiang H, Wu D, Simon MI: The transforming activity of activated $G$ alpha 12. FEBS Lett 1993;330:319-322.

14 Voyno-Yasenetskaya TA, Pace AM, Bourne HR: Mutant alpha subunits of G12 and G13 proteins induce neoplastic transformation of Rat-1 fibroblasts. Oncogene 1994;9:25592565

15 Xu N, Bradley L, Ambdukar I, Gutkind JS: A mutant alpha subunit of G12 potentiates the eicosanoid pathway and is highly oncogenic in NIH-3T3 cells. Proc Natl Acad Sci USA 1993;90:6741-6745.

16 Hiley E, McMullan R, Nurrish SJ: The Galpha12-RGS RhoGEF-RhoA signalling pathway regulates neurotransmitter release in $C$. elegans. EMBO J 2006;25:5884-5895. 
17 Kranenburg O, Poland M, van Horck FP, Drechsel D, Hall A, Moolenaar WH: Activation of RhoA by lysophosphatidic acid and Galpha12/13 subunits in neuronal cells: induction of neurite retraction. Mol Biol Cell 1999; 10:1851-1857.

-18 Moers A, Nurnberg A, Goebbels S, Wettschureck N, Offermanns S: Galpha12/Galpha13 deficiency causes localized overmigration of neurons in the developing cerebral and cerebellar cortices. Mol Cell Biol 2008; 28:1480-1488.

19 Jho EH, Malbon CC: Galpha12 and Galpha13 mediate differentiation of p19 mouse embryonal carcinoma cells in response to retinoic acid. J Biol Chem 1997;272:2446124467.

20 Dettlaff-Swiercz DA, Wettschureck N, Moers A, Huber K, Offermanns S: Characteristic defects in neural crest cell-specific Galphaq/Galpha11- and Galpha12/Galpha13deficient mice. Dev Biol 2005;282:174-182.

-21 Kourlas PJ, Strout MP, Becknell B, Veronese ML, Croce CM, Theil KS, Krahe R, Ruutu T, Knuutila S, Bloomfield CD, Caligiuri MA: Identification of a gene at 11q23 encoding a guanine nucleotide exchange factor: evidence for its fusion with MLL in acute myeloid leukemia. Proc Natl Acad Sci USA 2000;97:2145-2150.

-22 Kelly P, Moeller BJ, Juneja J, Booden MA, Der CJ, Daaka Y, Dewhirst MW, Fields TA, Casey PJ: The G12 family of heterotrimeric $\mathrm{G}$ proteins promotes breast cancer invasion and metastasis. Proc Natl Acad Sci USA 2006;103:8173-8178.

23 Kelly P, Stemmle LN, Madden JF, Fields TA, Daaka Y, Casey PJ: A role for the G12 family of heterotrimeric $\mathrm{G}$ proteins in prostate cancer invasion. J Biol Chem 2006;281:2648326490.

-24 Wirth A, Benyo Z, Lukasova M, Leutgeb B, Wettschureck N, Gorbey S, Orsy P, Horvath B, Maser-Gluth C, Greiner E, Lemmer B, Schutz G, Gutkind JS, Offermanns S: G12G13-LARG-mediated signaling in vascular smooth muscle is required for salt-induced hypertension. Nat Med 2008;14:64-68.

25 Aragay AM, Collins LR, Post GR, Watson AJ, Feramisco JR, Brown JH, Simon MI: G12 requirement for thrombin-stimulated gene expression and DNA synthesis in 1321N1 astrocytoma cells. J Biol Chem 1995;270: 20073-20077.

-26 Jho EH, Davis RJ, Malbon CC: C-jun aminoterminal kinase is regulated by Galpha12/ Galpha13 and obligate for differentiation of p19 embryonal carcinoma cells by retinoic acid. J Biol Chem 1997;272:24468-24474.

-27 Martin CB, Mahon GM, Klinger MB, Kay RJ, Symons M, Der CJ, Whitehead IP: The thrombin receptor, PAR-1, causes transformation by activation of Rho-mediated signaling pathways. Oncogene 2001;20:19531963.
$28 \mathrm{Gu}$ JL, Muller S, Mancino V, Offermanns S, Simon MI: Interaction of G alpha(12) with G alpha(13) and $G$ alpha(q) signaling pathways. Proc Natl Acad Sci USA 2002;99:93529357.

29 Offermanns S: In vivo functions of heterotrimeric G-proteins: Studies in Galpha-deficient mice. Oncogene 2001;20:1635-1642.

30 Gohla A, Schultz G, Offermanns S: Role for $\mathrm{G}(12) / \mathrm{G}(13)$ in agonist-induced vascular smooth muscle cell contraction. Circ Res 2000;87:221-227.

-31 Lutz S, Shankaranarayanan A, Coco C, Ridilla M, Nance MR, Vettel C, Baltus D, Evelyn CR, Neubig RR, Wieland T, Tesmer JJ: Structure of Galphaq-p63RhoGEF-RhoA complex reveals a pathway for the activation of RhoA by GPCRs. Science 2007;318:19231927.

32 Marinissen MJ, Servitja JM, Offermanns S, Simon MI, Gutkind JS: Thrombin proteaseactivated receptor-1 signals through $\mathrm{Gq}$ - and G13-initiated MAPK cascades regulating cJun expression to induce cell transformation. J Biol Chem 2003;278:46814-46825.

>33 Rojas RJ, Yohe ME, Gershburg S, Kawano T, Kozasa T, Sondek J: Galphaq directly activates p63RhoGEF and trio via a conserved extension of the Dbl homology-associated pleckstrin homology domain. J Biol Chem 2007;282:29201-29210.

34 Sagi SA, Seasholtz TM, Kobiashvili M, Wilson BA, Toksoz D, Brown JH: Physical and functional interactions of Galphaq with Rho and its exchange factors. J Biol Chem 2001; 276:15445-15452.

35 Vogt S, Grosse R, Schultz G, Offermanns S: Receptor-dependent RhoA activation in G12/G13-deficient cells: genetic evidence for an involvement of gq/G11. J Biol Chem 2003; 278:28743-28749.

36 Yuan J, Slice LW, Rozengurt E: Activation of protein kinase d by signaling through Rho and the alpha subunit of the heterotrimeric G protein G13. J Biol Chem 2001;276:3861938627.

$>37$ Hepler JR, Gilman AG: G proteins. Trends Biochem Sci 1992;17:383-387.

38 Neer EJ: Heterotrimeric G proteins: organizers of transmembrane signals. Cell 1995;80: 249-257.

39 Ross EM, Wilkie TM: GTPase-activating proteins for heterotrimeric $\mathrm{G}$ proteins: regulators of $G$ protein signaling (RGS) and RGSlike proteins. Annu Rev Biochem 2000;69: 795-827.

40 Zerangue N, Jan LY: G-protein signaling: fine-tuning signaling kinetics. Curr Biol 1998;8:R313-R316.

41 Riobo NA, Manning DR: Receptors coupled to heterotrimeric $\mathrm{G}$ proteins of the G12 family. Trends Pharmacol Sci 2005;26:146-154.
42 Sugimoto N, Takuwa N, Okamoto H, Sakurada $S$, Takuwa Y: Inhibitory and stimulatory regulation of Rac and cell motility by the G12/13-Rho and Gi pathways integrated downstream of a single G-protein-coupled sphingosine-1-phosphate receptor isoform. Mol Cell Biol 2003;23:1534-1545.

43 Macrez-Lepretre N, Kalkbrenner F, Morel JL, Schultz G, Mironneau J: G protein heterotrimer Galpha13betalgamma3 couples the angiotensin atla receptor to increases in cytoplasmic $\mathrm{Ca}^{2+}$ in rat portal vein myocytes. J Biol Chem 1997;272:10095-10102.

44 Yamaguchi Y, Katoh H, Negishi M: N-terminal short sequences of alpha subunits of the G12 family determine selective coupling to receptors. J Biol Chem 2003;278:1493614939.

45 Hermans E: Biochemical and pharmacological control of the multiplicity of coupling at G-protein-coupled receptors. Pharmacol Ther 2003;99:25-44.

46 Kuniyeda K, Okuno T, Terawaki K, Miyano M, Yokomizo T, Shimizu T: Identification of the intracellular region of the leukotriene $\mathrm{B}_{4}$ receptor type 1 that is specifically involved in Gi activation. J Biol Chem 2007;282:39984006.

47 Ponimaskin EG, Profirovic J, Vaiskunaite R, Richter DW, Voyno-Yasenetskaya TA: 5-Hydroxytryptamine 4(a) receptor is coupled to the Galpha subunit of heterotrimeric G13 protein. J Biol Chem 2002;277:20812-20819.

48 Zhang L, DiLizio C, Kim D, Smyth EM, Manning DR: The G12 family of G proteins as a reporter of thromboxane $\mathrm{A}_{2}$ receptor activity. Mol Pharmacol 2006;69:1433-1440.

49 Kozasa T, Gilman AG: Purification of recombinant $\mathrm{G}$ proteins from sf9 cells by hexahistidine tagging of associated subunits. Characterization of alpha 12 and inhibition of adenylyl cyclase by alpha z. J Biol Chem 1995;270:1734-1741.

50 Singer WD, Miller RT, Sternweis PC: Purification and characterization of the alpha subunit of G13. J Biol Chem 1994;269:1979619802.

-51 Kozasa T, Jiang X, Hart MJ, Sternweis PM, Singer WD, Gilman AG, Bollag G, Sternweis PC: P115 RhoGEF, a GTPase activating protein for Galpha12 and Galpha13. Science 1998;280:2109-2111.

52 Suzuki N, Nakamura S, Mano H, Kozasa T: Galpha 12 activates Rho GTPase through tyrosine-phosphorylated leukemia-associated RhoGEF. Proc Natl Acad Sci USA 2003;100: 733-738.

53 Wells CD, Liu MY, Jackson M, Gutowski S, Sternweis PM, Rothstein JD, Kozasa T, Sternweis PC: Mechanisms for reversible regulation between G13 and Rho exchange factors. J Biol Chem 2002;277:1174-1181.

54 Chen Z, Singer WD, Sternweis PC, Sprang SR: Structure of the p115RhoGEF rgRGS domain-Galpha13/i1 chimera complex suggests convergent evolution of a GTPase activator. Nat Struct Mol Biol 2005;12:191-197. 
-55 Fukuhara S, Murga C, Zohar M, Igishi T, Gutkind JS: A novel PDZ domain containing guanine nucleotide exchange factor links heterotrimeric $\mathrm{G}$ proteins to Rho. J Biol Chem 1999;274:5868-5879.

-56 Kreutz B, Yau DM, Nance MR, Tanabe S, Tesmer JJ, Kozasa T: A new approach to producing functional Galpha subunits yields the activated and deactivated structures of Galpha(12/13) proteins. Biochemistry 2006; 45:167-174.

-57 Tesmer VM, Kawano T, Shankaranarayanan A, Kozasa T, Tesmer JJ: Snapshot of activated $\mathrm{G}$ proteins at the membrane: the GalphaqGRK2-gbetagamma complex. Science 2005; 310:1686-1690.

>58 Hart MJ, Jiang X, Kozasa T, Roscoe W, Singer WD, Gilman AG, Sternweis PC, Bollag G: Direct stimulation of the guanine nucleotide exchange activity of p115 RhoGEF by Galpha13. Science 1998;280:2112-2114.

-59 Chen Z, Wells CD, Sternweis PC, Sprang SR: Structure of the rgRGS domain of p115RhoGEF. Nat Struct Biol 2001;8:805809.

60 Longenecker KL, Lewis ME, Chikumi H, Gutkind JS, Derewenda ZS: Structure of the RGS-like domain from PDZ-RhoGEF: linking heterotrimeric $G$ protein-coupled signaling to Rho GTPases. Structure 2001;9: 559-569.

-61 Grabocka E, Wedegaertner PB: Functional consequences of $\mathrm{G}$ alpha 13 mutations that disrupt interaction with p115RhoGEF. Oncogene 2005;24:2155-2165.

-62 Nakamura S, Kreutz B, Tanabe S, Suzuki N, Kozasa T: Critical role of lysine 204 in switch I region of Galpha13 for regulation of p115RhoGEF and leukemia-associated RhoGEF. Mol Pharmacol 2004;66:1029-1034.

-63 Chen Z, Singer WD, Wells CD, Sprang SR, Sternweis PC: Mapping the Galpha13 binding interface of the rgRGS domain of p115RhoGEF. J Biol Chem 2003;278:99129919.

-64 Bhattacharyya R, Wedegaertner PB: Mutation of an n-terminal acidic-rich region of p115-RhoGEF dissociates alpha13 binding and alpha13-promoted plasma membrane recruitment. FEBS Lett 2003;540:211-216.

65 Jones TL, Gutkind JS: Galpha12 requires acylation for its transforming activity. Biochemistry 1998;37:3196-3202.

-66 Ponimaskin E, Behn H, Adarichev V, VoynoYasenetskaya TA, Offermanns S, Schmidt MF: Acylation of Galpha(13) is important for its interaction with thrombin receptor, transforming activity and actin stress fiber formation. FEBS Lett 2000;478:173-177.

-67 Veit M, Nurnberg B, Spicher K, Harteneck C, Ponimaskin E, Schultz G, Schmidt MF: The alpha-subunits of G-proteins G12 and G13 are palmitoylated, but not amidically myristoylated. FEBS Lett 1994;339:160-164.
68 Bhattacharyya R, Wedegaertner PB: Galpha 13 requires palmitoylation for plasma membrane localization, Rho-dependent signaling, and promotion of p115-RhoGEF membrane binding. J Biol Chem 2000;275: 14992-14999.

69 Waheed AA, Jones TL: Hsp90 interactions and acylation target the $\mathrm{G}$ protein Galpha 12 but not Galpha 13 to lipid rafts. J Biol Chem 2002;277:32409-32412.

70 Tu Y, Wang J, Ross EM: Inhibition of brain $\mathrm{Gz}$ gap and other RGS proteins by palmitoylation of $\mathrm{G}$ protein alpha subunits. Science 1997;278:1132-1135.

71 Fields TA, Casey PJ: Phosphorylation of Gz alpha by protein kinase $\mathrm{C}$ blocks interaction with the beta gamma complex. J Biol Chem 1995;270:23119-23125.

72 Kozasa T, Gilman AG: Protein kinase C phosphorylates G12 alpha and inhibits its interaction with $\mathrm{g}$ beta gamma. J Biol Chem 1996;271:12562-12567.

73 Lounsbury KM, Casey PJ, Brass LF, Manning DR: Phosphorylation of $\mathrm{Gz}$ in human platelets. Selectivity and site of modification. J Biol Chem 1991;266:22051-22056.

74 Lounsbury KM, Schlegel B, Poncz M, Brass LF, Manning DR: Analysis of $\mathrm{Gz}$ alpha by site-directed mutagenesis. Sites and specificity of protein kinase C-dependent phosphorylation. J Biol Chem 1993;268:3494-3498.

75 Offermanns S, Hu YH, Simon MI: Galpha12 and Galpha13 are phosphorylated during platelet activation. J Biol Chem 1996;271: 26044-26048.

76 Wang J, Ducret A, Tu Y, Kozasa T, Aebersold R, Ross EM: RGSz1, a Gz-selective RGS protein in brain. Structure, membrane association, regulation by Galphaz phosphorylation, and relationship to a Gz GTPaseactivating protein subfamily. J Biol Chem 1998;273:26014-26025.

77 Glick JL, Meigs TE, Miron A, Casey PJ: RGSz1, a Gz-selective regulator of $\mathrm{G}$ protein signaling whose action is sensitive to the phosphorylation state of $\mathrm{Gz}$ alpha. J Biol Chem 1998;273:26008-26013.

-78 Van der Linden AM, Moorman C, Cuppen E, Korswagen HC, Plasterk RH: Hyperactivation of the G12-mediated signaling pathway in Caenorhabditis elegans induces a developmental growth arrest via protein kinase C. Curr Biol 2003;13:516-521.

79 Dhanasekaran N, Prasad MV, Wadsworth SJ, Dermott JM, van Rossum G: Protein kinase $\mathrm{C}$-dependent and -independent activation of $\mathrm{Na}^{+} / \mathrm{H}^{+}$exchanger by $\mathrm{G}$ alpha 12 class of G proteins. J Biol Chem 1994;269:1180211806.

80 Kelly P, Casey PJ, Meigs TE: Biologic functions of the G12 subfamily of heterotrimeric G proteins: growth, migration, and metastasis. Biochemistry 2007;46:6677-6687.

-81 Sternweis PC, Carter AM, Chen Z, Danesh SM, Hsiung YF, Singer WD: Regulation of Rho guanine nucleotide exchange factors by $\mathrm{G}$ proteins. Adv Protein Chem 2007;74:189-228.
82 Hall A: Rho GTPases and the actin cytoskeleton. Science 1998;279:509-514.

$>83$ Vazquez-Prado J, Miyazaki H, Castellone MD, Teramoto H, Gutkind JS: Chimeric G alpha $i 2 / \mathrm{G}$ alpha 13 proteins reveal the structural requirements for the binding and activation of the RGS-like (RGL)-containing Rho guanine nucleotide exchange factors (GEFs) by G alpha 13. J Biol Chem 2004;279: 54283-54290.

84 Kreutz B, Hajicek N, Yau DM, Nakamura S, Kozasa T: Distinct regions of Galpha13 participate in its regulatory interactions with RGS homology domain-containing RhoGEFs. Cell Signal 2007;19:1681-1689.

$>85$ Chikumi H, Fukuhara S, Gutkind JS: Regulation of $\mathrm{G}$ protein-linked guanine nucleotide exchange factors for Rho, PDZ-RhoGEF, and LARG by tyrosine phosphorylation: Evidence of a role for focal adhesion kinase. J Biol Chem 2002;277:12463-12473.

-86 Hamazaki Y, Kojima H, Mano H, Nagata Y, Todokoro K, Abe T, Nagasawa T: Tec is involved in G-protein-coupled receptor- and integrin-mediated signalings in human blood platelets. Oncogene 1998;16:27732779 .

-87 Jiang Y, Ma W, Wan Y, Kozasa T, Hattori S, Huang XY: The G protein G alpha12 stimulates Bruton's tyrosine kinase and a rasGAP through a conserved $\mathrm{PH} / \mathrm{BM}$ domain. Nature 1998;395:808-813.

88 Mao J, Xie W, Yuan H, Simon MI, Mano H, Wu D: Tec/Bmx non-receptor tyrosine kinases are involved in regulation of Rho and serum response factor by Galpha12/13. EMBO J 1998; 17:5638-5646.

89 Gohla A, Harhammer R, Schultz G: The Gprotein G13 but not G12 mediates signaling from lysophosphatidic acid receptor via epidermal growth factor receptor to Rho. J Biol Chem 1998;273:4653-4659.

90 Chikumi H, Barac A, Behbahani B, Gao Y, Teramoto H, Zheng Y, Gutkind JS: Homoand hetero-oligomerization of PDZ-RhoGEF, LARG and p115RhoGEF by their C-terminal region regulates their in vivo Rho GEF activity and transforming potential. Oncogene 2004;23:233-240.

-91 Eisenhaure TM, Francis SA, Willison LD, Coughlin SR, Lerner DJ: The Rho guanine nucleotide exchange factor Lsc homo-oligomerizes and is negatively regulated through domains in its carboxyl terminus that are absent in novel splenic isoforms. J Biol Chem 2003;278:30975-30984.

92 Grabocka E, Wedegaertner PB: Disruption of oligomerization induces nucleocytoplasmic shuttling of leukemia-associated Rho guanine-nucleotide exchange factor. Mol Pharmacol 2007;72:993-1002.

$>93$ Wells CD, Gutowski S, Bollag G, Sternweis PC: Identification of potential mechanisms for regulation of p115 RhoGEF through analysis of endogenous and mutant forms of the exchange factor. J Biol Chem 2001;276: 28897-28905 
\$94 Kitzing TM, Sahadevan AS, Brandt DT, Knieling H, Hannemann S, Fackler OT, Grosshans J, Grosse R: Positive feedback between Dia1, LARG, and RhoA regulates cell morphology and invasion. Genes Dev 2007;21:1478-1483.

$\checkmark 95$ Bhattacharyya R, Wedegaertner PB: Characterization of $\mathrm{G}$ alpha 13-dependent plasma membrane recruitment of p115RhoGEF. Biochem J 2003;371:709-720.

96 Kuner R, Swiercz JM, Zywietz A, Tappe A, Offermanns S: Characterization of the expression of PDZ-RhoGEF, LARG and G(alpha)12/G(alpha)13 proteins in the murine nervous system. Eur J Neurosci 2002; 16:2333-2341.

$\checkmark 97$ Togashi H, Nagata K, Takagishi M, Saitoh $\mathrm{N}$, Inagaki M: Functions of a Rho-specific guanine nucleotide exchange factor in neurite retraction. Possible role of a prolinerich motif of KIAA0380 in localization. J Biol Chem 2000;275:29570-29578.

$\checkmark 98$ Banerjee J, Wedegaertner PB: Identification of a novel sequence in PDZ-RhoGEF that mediates interaction with the actin cytoskeleton. Mol Biol Cell 2004;15:17601775.

99 Wong K, Van Keymeulen A, Bourne HR: PDZ-RhoGEF and myosin II localize RhoA activity to the back of polarizing neutrophil-like cells. J Cell Biol 2007;179:11411148.

100 Taya S, Inagaki N, Sengiku H, Makino H, Iwamatsu A, Urakawa I, Nagao K, Kataoka S, Kaibuchi K: Direct interaction of insulin-like growth factor-1 receptor with leukemia-associated RhoGEF. J Cell Biol 2001; 155:809-820.

-101 Aurandt J, Vikis HG, Gutkind JS, Ahn N, Guan KL: The semaphorin receptor plexinB1 signals through a direct interaction with the Rho-specific nucleotide exchange factor, LARG. Proc Natl Acad Sci USA 2002; 99:12085-12090.

-102 Hirotani M, Ohoka Y, Yamamoto T, Nirasawa H, Furuyama T, Kogo M, Matsuya T, Inagaki S: Interaction of plexin-B1 with PDZ domain-containing Rho guanine nucleotide exchange factors. Biochem Biophys Res Commun 2002;297:32-37.

-103 Perrot V, Vazquez-Prado J, Gutkind JS: Plexin B regulates Rho through the guanine nucleotide exchange factors leukemiaassociated Rho GEF (LARG) and PDZRhoGEF. J Biol Chem 2002;277:4311543120.

-104 Swiercz JM, Kuner R, Behrens J, Offermanns S: Plexin-B1 directly interacts with PDZ-RhoGEF/LARG to regulate RhoA and growth cone morphology. Neuron 2002;35: 51-63.

- 105 Meigs TE, Fedor-Chaiken M, Kaplan DD, Brackenbury R, Casey PJ: Galpha12 and Galpha13 negatively regulate the adhesive functions of cadherin. J Biol Chem 2002; 277:24594-24600.
106 Meigs TE, Fields TA, McKee DD, Casey PJ: Interaction of Galpha 12 and Galpha 13 with the cytoplasmic domain of cadherin provides a mechanism for beta-catenin release. Proc Natl Acad Sci USA 2001;98:519_ 524.

107 Shi CS, Sinnarajah S, Cho H, Kozasa T, Kehrl JH: G13alpha-mediated PYK2 activation. PYK2 is a mediator of G13alpha-induced serum response element-dependent transcription. J Biol Chem 2000;275:2447024476.

108 Basile JR, Barac A, Zhu T, Guan KL, Gutkind JS: Class IV semaphorins promote angiogenesis by stimulating Rho-initiated pathways through plexin-B. Cancer Res 2004;64:5212-5224.

109 Bourguignon LY, Gilad E, Brightman A, Diedrich F, Singleton P: Hyaluronan-CD44 interaction with leukemia-associated RhoGEF and epidermal growth factor receptor promotes Rho/Ras co-activation, phospholipase $\mathrm{C}$ epsilon- $\mathrm{Ca}^{2+}$ signaling, and cytoskeleton modification in head and neck squamous cell carcinoma cells. J Biol Chem 2006;281:14026-14040.

$>110$ Yamada T, Ohoka Y, Kogo M, Inagaki S: Physical and functional interactions of the lysophosphatidic acid receptors with PDZ domain-containing Rho guanine nucleotide exchange factors (RhoGEFs). J Biol Chem 2005;280:19358-19363.

111 Zhang H, Wang L, Kao S, Whitehead IP, Hart MJ, Liu B, Duus K, Burridge K, Der CJ, $\mathrm{Su}$ L: Functional interaction between the cytoplasmic leucine-zipper domain of HIV-1 gp41 and p115-RhoGEF. Curr Biol 1999;9:1271-1274.

112 Shi CS, Kehrl JH: PYK2 links G/q)alpha and $\mathrm{G}(13)$ alpha signaling to NF- $\mathrm{B}$ activation. J Biol Chem 2001;276:31845-31850.

113 Booden MA, Siderovski DP, Der CJ: Leukemia-associated Rho guanine nucleotide exchange factor promotes $\mathrm{G}$ alpha q-coupled activation of RhoA. Mol Cell Biol 2002;22: 4053-4061

114 Chikumi H, Vazquez-Prado J, Servitja JM, Miyazaki H, Gutkind JS: Potent activation of RhoA by Galpha $\mathrm{q}$ and Gq-coupled receptors. J Biol Chem 2002;277:2713027134.

115 Klages B, Brandt U, Simon MI, Schultz G, Offermanns S: Activation of G12/G13 results in shape change and Rho/Rho-kinasemediated myosin light chain phosphorylation in mouse platelets. J Cell Biol 1999;144: 745-754.

116 Ross EM: Signal sorting and amplification through G-protein-coupled receptors. Neuron 1989;3:141-152.

-117 Meigs TE, Juneja J, DeMarco CT, Stemmle LN, Kaplan DD, Casey PJ: Selective uncoupling of $\mathrm{G}$ alpha 12 from Rho-mediated signaling. J Biol Chem 2005;280:1804918055.
118 Wang Q, Liu M, Kozasa T, Rothstein JD, Sternweis PC, Neubig RR: Thrombin and lysophosphatidic acid receptors utilize distinct RhoGEFs in prostate cancer cells. J Biol Chem 2004;279:28831-28834.

119 Yau DM, Yokoyama N, Goshima Y, Siddiqui ZK, Siddiqui SS, Kozasa T: Identification and molecular characterization of the G alpha12-Rho guanine nucleotide exchange factor pathway in Caenorhabditis elegans. Proc Natl Acad Sci USA 2003;100: 14748-14753.

120 McMullan R, Hiley E, Morrison P, Nurrish SJ: Rho is a presynaptic activator of neurotransmitter release at pre-existing synapses in C. elegans. Genes Dev 2006;20:6576.

121 Williams SL, Lutz S, Charlie NK, Vettel C, Ailion M, Coco C, Tesmer JJ, Jorgensen EM, Wieland T, Miller KG: Trio's Rho-specific GEF domain is the missing Galpha $\mathrm{q}$ effector in C. elegans. Genes Dev 2007;21: 2731-2746.

122 Fukuhara S, Chikumi H, Gutkind JS: RGScontaining RhoGEFs: the missing link between transforming $\mathrm{G}$ proteins and Rho? Oncogene 2001;20:1661-1668.

123 Radhika V, Dhanasekaran N: Transforming G proteins. Oncogene 2001;20:16071614.

124 Vaiskunaite R, Adarichev V, Furthmayr H, Kozasa T, Gudkov A, Voyno-Yasenetskaya TA: Conformational activation of radixin by G13 protein alpha subunit. J Biol Chem 2000;275:26206-26212.

125 Liu G, Voyno-Yasenetskaya TA: Radixin stimulates $\mathrm{Racl}$ and $\mathrm{Ca}^{2+} /$ calmodulin-dependent kinase, CaMKII: cross-talk with Galpha13 signaling. J Biol Chem 2005;280: 39042-39049.

126 Bos JL: The ras gene family and human carcinogenesis. Mutat Res 1988;195:255-271.

127 Boettner B, Van Aelst L: The role of Rho GTPases in disease development. Gene 2002;286:155-174.

128 Sahai E, Marshall CJ: Rho-GTPases and cancer. Nat Rev Cancer 2002;2:133-142.

129 Zinovyeva M, Sveshnikova E, Visser J, Belyavsky A: Molecular cloning, sequence and expression pattern analysis of the mouse orthologue of the leukemia-associated guanine nucleotide exchange factor. Gene 2004;337:181-188.

130 Rujkijyanont P, Beyene J, Wei K, Khan F, Dror Y: Leukaemia-related gene expression in bone marrow cells from patients with the preleukaemic disorder Shwachman-diamond syndrome. Br J Haematol 2007;137: 537-544.

131 Etienne-Manneville S, Hall A: Rho GTPases in cell biology. Nature 2002;420:629635.

132 Ridley AJ: Rho GTPases and cell migration. J Cell Sci 2001;114:2713-2722. 
133 Sugden PH, Clerk A: 'Stress-responsive' mitogen-activated protein kinases (c-Jun Nterminal kinases and p38 mitogen-activated protein kinases) in the myocardium. Circ Res 1998;83:345-352.

134 Maruyama Y, Nishida M, Sugimoto Y, Tanabe S, Turner JH, Kozasa T, Wada T, Nagao T, Kurose H: Galpha(12/13) mediates alpha(1)-adrenergic receptor-induced cardiac hypertrophy. Circ Res 2002;91:961969.

135 Rubtsov A, Strauch P, Digiacomo A, Hu J, Pelanda R, Torres RM: Lsc regulates marginal-zone $\mathrm{B}$ cell migration and adhesion and is required for the IgM T-dependent antibody response. Immunity 2005;23: 527-538.

136 Hart MJ, Sharma S, el Masry N, Qiu RG, McCabe P, Polakis P, Bollag G: Identification of a novel guanine nucleotide exchange factor for the Rho GTPase. J Biol Chem 1996;271:25452-25458.
137 Whitehead IP, Khosravi-Far R, Kirk H, Trigo-Gonzalez G, Der CJ, Kay R: Expression cloning of lsc, a novel oncogene with structural similarities to the Dbl family of guanine nucleotide exchange factors. J Biol Chem 1996;271:18643-18650.

138 Aasheim HC, Pedeutour F, Smeland EB: Characterization, expression and chromosomal localization of a human gene homologous to the mouse Lsc oncogene, with strongest expression in hematopoietic tissues. Oncogene 1997;14:1747-1752.

139 Francis SA, Shen X, Young JB, Kaul P, Lerner DJ: Rho GEF Lsc is required for normal polarization, migration, and adhesion of formyl-peptide-stimulated neutrophils. Blood 2006;107:1627-1635.

140 Guan KL, Rao Y: Signalling mechanisms mediating neuronal responses to guidance cues. Nat Rev Neurosci 2003;4:941-956.

141 Postma FR, Jalink K, Hengeveld T, Moolenaar WH: Sphingosine-1-phosphate rapidly induces Rho-dependent neurite retraction: action through a specific cell surface receptor. EMBO J 1996;15:2388-2392.
142 Vikis HG, Li W, Guan KL: The plexin-B1/ Rac interaction inhibits PAK activation and enhances Sema4D ligand binding. Genes Dev 2002;16:836-845.

143 Kasai K, Takahashi M, Osumi N, Sinnarajah S, Takeo T, Ikeda H, Kehrl JH, Itoh G, Arnheiter H: The G12 family of heterotrimeric $\mathrm{G}$ proteins and Rho GTPase mediate sonic hedgehog signalling. Genes Cells 2004;9:49-58.

144 Honma S, Saika M, Ohkubo S, Kurose H, Nakahata N: Thromboxane $\mathrm{A}_{2}$ receptormediated G12/13-dependent glial morphological change. Eur J Pharmacol 2006;545: 100-108.

145 Suzuki N, Tsumoto K, Hajicek N, Daigo K, Tokita R, Minami S, Kodama T, Hamakubo T, Kozasa T: Activation of Leukemia-associated RhoGEF by Galpha13 with significant conformational rearrangements in the interface. J Biol Chem 2008, in press. 